\title{
Enhanced recovery after surgery for liver resection
}

\author{
Charing CN Chong *, WY Chung, YS Cheung, Andrew KY Fung, Anthony KW Fong, HT Lok, John Wong, \\ KF Lee, Simon KC Chan, Paul BS Lai
}

\section{A B S T R A C T}

Introduction: Enhanced recovery after surgery (ERAS) reduces postoperative length of hospital stay and patient stress response to liver surgery. The aim of the present study was to evaluate the efficacy and feasibility of an ERAS programme for liver resection.

Methods: A multidisciplinary ERAS protocol was implemented for both open and laparoscopic liver resection in a tertiary hospital in Hong Kong. The clinical outcomes of patients who underwent liver resection and underwent the ERAS perioperative programme were compared with those who received a conventional perioperative programme between September 2015 and July 2016. Propensity score matching analysis was used to minimise background differences.

Results: A total of 20 patients who underwent liver resection were recruited to the ERAS programme. Their clinical outcomes were compared with another 20 patients who received hepatectomy under a conventional perioperative programme after propensity score matching. The ERAS programme was associated with a significantly shorter length of hospital stay $(\mathrm{P}=0.033)$ without an increase in

This article was published on $27 \mathrm{Mar}$ 2019 at www.hkmj.org. complication rates in patients who underwent open liver resection. There was no such significant

association in patients who underwent laparoscopic liver resection. No patients required readmission in this cohort.

Conclusions: The ERAS perioperative programme for liver resection is safe and feasible. It significantly shortened the hospital stay after open liver resection but not after laparoscopic liver resection.

\section{Hong Kong Med J 2019;25:94-10

\author{
CCN Chong *, FHKAM (Surgery) \\ ${ }^{1}$ WY Chung, MSc (Nursing) \\ ${ }^{1}$ AKY Fung, FHKAM (Surgery) \\ ${ }^{1}$ AKW Fong, FHKAM (Surgery) \\ ${ }^{1}$ HT Lok, FHKAM (Surgery) \\ ${ }^{1}$ KF Lee, FHKAM (Surgery) \\ SKC Chan, FHKAM (Anaesthesia) \\ ${ }^{1}$ PBS Lai, FHKAM (Surgery)
} \\ ${ }^{1}$ YS Cheung, FHKAM (Surgery) \\ 1 J Wong, FHKAM (Surgery)}

https://doi.org/10.12809/hkmj187656

1 Department of Surgery, Prince of Wales Hospital, The Chinese University of Hong Kong, Shatin, Hong Kong

2 Department of Anaesthesia, Prince of Wales Hospital, The Chinese University of Hong Kong, Shatin, Hong Kong

* Corresponding author: chongcn@surgery.cuhk.edu.hk

New knowledge added by this study

- Enhanced recovery after surgery (ERAS) for liver resection is safe and feasible in Hong Kong.

- The ERAS programme significantly shortened hospital stays after open liver resection, but not after laparoscopic liver resection.

Implications for clinical practice or policy

- The ERAS programme can be safety implemented for liver resection in Hong Kong.

\section{Introduction}

Enhanced recovery after surgery (ERAS) is a multimodal pathway developed to improve recovery after major surgery. Since its formal introduction in the 1990s, ERAS has been adopted quickly because of the cost efficiency derived from its reduction in length of hospital stays, an important issue in the context of current rapidly increasing healthcare costs and the consequent need for optimisation. ${ }^{1,2}$ Application of ERAS integrates various medical interventions involving surgeons, anaesthetists, physiotherapists, dieticians, and nurses. ${ }^{3}$ The benefits of ERAS have been well proven in colectomy ${ }^{4-7}$ Liver cancer is the fourth leading cause of cancer death in both sexes worldwide. ${ }^{8}$ Liver resection remains the mainstay of curative treatment for liver cancer. Liver resection is associated with a high rate of postoperative morbidity ranging from $15 \%$ to $48 \% \%^{9,10}$ and a postoperative hospital stay of 9 to 15 days. ${ }^{11}$ The high rates of complications lead to prolonged hospital stay and increase costs of hospitalisation.

An ERAS programme combines a number of elements that aim to enhance postoperative recovery, facilitate earlier discharge, and reduce surgical stress response.,4 It mainly focuses on minimising the impact of surgery on patient homeostasis. ${ }^{12}$ 
The reduction of postoperative physiological stress by attenuation of the neurohormonal response to the surgical intervention not only provides the basis for a faster recovery but also diminishes the risk of organ dysfunction and complications..$^{13}$ Programmes for ERAS consist of well-organised pathways of clinical interventions that begin with out-patient preoperative information, counselling, and physical optimisation; proceed to pre-, intra-, and post-operative protocol-driven actions; and end with patient discharge following pre-established criteria. ${ }^{14}$ The main pillars of ERAS are extensive preoperative counselling, no bowel preparation, no sedative premedication, no preoperative fasting, preoperative carbohydrate loading, tailored anaesthesiology, perioperative intravenous fluid restriction, non-opioid pain management, no routine use of drains and nasogastric tubes, early removal of the urinary catheter, and early postoperative feeding and mobilisation. ${ }^{15,16}$ Several major studies have suggested that ERAS is feasible and significantly reduces complications and the length of hospital stay for patients undergoing colonic resection. ${ }^{4-7,17}$ Furthermore, ERAS has been successfully applied to urological, $^{18}$ cardiovascular, ${ }^{19}$ gynaecological, ${ }^{20}$ orthopaedic, ${ }^{21}$ and thoracic surgeries. ${ }^{22}$ However, the literature on ERAS after liver resection is limited. The aim of the present study was to evaluate the safety and efficacy of an ERAS programme for open or laparoscopic liver resection.

\section{Methods}

\section{Patients}

This was a prospective feasibility study carried out in a tertiary academic hospital. The inclusion criteria recruited all consecutive patients undergoing elective liver resection who were aged 18 to 70 years, with American Society of Anesthesiologists (ASA) grade I or II, with no severe physical disabilities, who required no assistance with activities of daily living, and with informed consent available. Patients undergoing emergency surgery, who had received preoperative portal vein embolisation, who were expected to receive concomitant procedures other than cholecystectomy, who were mentally incapable of written consent, and women who were pregnant were excluded.

During the same period, 42 patients who fulfilled the same inclusion criteria underwent liver resection and a conventional perioperative programme, as the On-Q Pain Buster system (I-Flow Corporation, Lake Forest [CA], US) was not available for financial reasons. None of the control patients were assigned to that group because they refused the ERAS programme. Propensity score matching analysis was used to minimise bias and confounding factors in patient selection, and 20 matched pairs of patients were generated for comparison.

\section{快速康復肝藏切除手術}

\section{莊清寧、鍾詠茵、張宇新、馮啟業、方廣偉、駱漢庭、黃創、 李傑輝、陳建昌、賴寶山}

引言：快速康復（ERAS）可減少術後住院時間和患者對肝臟手術的 應激反應。本研究旨在評估ERAS肝切除術的有效性和可行性。

方法 : 在香港一家三級醫院實施開放式和腹腔鏡肝切除術的多學科 ERAS 協議。將2015年9月至2016年7月期間接受肝切除術並接受 ERAS計劃的患者的臨床結果與常規手術計劃的患者進行比較。我們 利用了傾向評分匹配分析以減少背景差異。

結果：共有 20 名接受肝切除術的患者被納入ERAS計劃。他們的臨床 結果與另外 20 名接受常規肝切除術的患者進行比較。在接受開腹肝切 除術的患者中, ERAS計劃顯著縮短了住院時間（ $\mathrm{P}=0.033)$ 而沒有增 加併發症發生率 ; 在接受腹腔鏡肝切除術的患者中沒有這種顯著相關 性。沒有患者需要重新入院。

結論：快速康復（ERAS）肝切除術安全可行。它顯著縮短了肝切除 術後的住院時間, 但在腹腔鏡肝切除術中成效未見顯著。

\section{Surgery}

The same team of hepatobiliary surgeons experienced in both laparoscopic and liver surgery performed all operations. Our open and laparoscopic techniques have been described previously. ${ }^{23}$ In brief, open hepatectomy was performed via right subcostal incisions with upward midline extensions and in some cases with left subcostal extensions. In most cases, the liver was mobilised in standard fashion before parenchymal transection, whereas in the rest, we adopted the anterior approach or the hanging technique. Liver transection was performed with a cavitron ultrasonic surgical aspirator (Valleylab, Boulder [CO], US) and TissueLink (TissueLink Medical Inc, Dover [DE], US). For laparoscopic hepatectomy, a combination of TissueLink and LigaSure (Valleylab) were used for liver transection. The Pringle manoeuvre was not routinely applied during liver resection. Endovascular staplers (Tyco Healthcare, Norwalk [CT], US) were used to divide larger vascular pedicles.

\section{Fast-track perioperative programmes}

Details of the ERAS programme and the conventional perioperative programme are summarised in Table 1. The design of the ERAS programme was based on consensus between our surgeons, anaesthetists, physiotherapists, dieticians and nurses, who reviewed the relevant literature and made appropriate adjustments to suit the local situation. Patients who were to undergo elective hepatectomy were first screened in an out-patient clinic or in wards for eligibility for the ERAS programme. Patients who fulfilled the inclusion and exclusion criteria were interviewed by the principal investigator or co- 
investigators for the recruitment and preoperative counselling. A guided tour on surgical ward led by a trained nurse and an information booklet about the preoperative guidance were given to each patient. The booklet described the method used for respiratory rehabilitation, daily medical events after admission, daily mobilisation goals, and nutritional goals after the operation. The patient was seen at a preoperative anaesthesia clinic for preoperative assessment of risk adjustment and education about the fast-track anaesthetic and postoperative pain management, especially during mobilisation.

All patients received a $20-\mathrm{mL}$ local infiltration of local anaesthesia $(0.25 \%$ levobupivacaine $)$ followed by continuous wound instillation at 4 $\mathrm{mL} / \mathrm{h}$ for $72 \mathrm{~h}$ using the On-Q Pain Buster System balloon pump (I-Flow Corporation). Pain control was supplemented using opioid-sparing multimodal analgesia, including oral paracetamol and nonsteroidal anti-inflammatory drugs. For minimally invasive liver resection, continuous infiltration of the wound with local anaesthetic agents was used and early mobilisation started on postoperative day 0 . The principal investigator held regular audit meetings with the research team and medical/ nursing staff to ensure protocol compliance.

TABLE I. Summary of the ERAS and conventional perioperative programmes

\begin{tabular}{|c|c|c|}
\hline & ERAS programme & Conventional programme \\
\hline \multicolumn{3}{|l|}{ Preoperative phase } \\
\hline $\begin{array}{l}\text { Pre-hepatectomy workup } \\
\text { (surgery) }\end{array}$ & $\begin{array}{l}\text { - Scheduling of surgery } \\
\text { - Information about fast-track perioperative programme; } \\
\text { discuss discharge on postoperative day } 5 \text { if possible } \\
\text { - Informed consent }\end{array}$ & $\begin{array}{l}\text { - Scheduling of surgery } \\
\text { - Informed consent }\end{array}$ \\
\hline $\begin{array}{l}\text { Preoperative clinic } \\
\text { (anaesthesia) }\end{array}$ & $\begin{array}{l}\text { - Pre-assessment for risk adjustment } \\
\text { - Discussion focusing on fast-track anaesthetic and } \\
\text { postoperative pain management } \\
\text { - Explanation of pain assessment using visual analogue } \\
\text { scale }\end{array}$ & $\begin{array}{l}\text { - Pre-assessment for risk adjustment } \\
\text { - Explanation of IV PCA for postoperative pain } \\
\text { management } \\
\text { - Explanation of pain assessment using visual } \\
\text { analogue scale }\end{array}$ \\
\hline $\begin{array}{l}\text { Preadmission counselling and } \\
\text { guided tour of surgical ward }\end{array}$ & Yes & No tour \\
\hline \multicolumn{3}{|l|}{ Day of admission } \\
\hline Bowel preparation & No & No \\
\hline Diet & Last meal 6 hours before surgery & Last meal midnight the night before surgery \\
\hline Intravenous fluid & No intravenous fluid preoperatively & $\begin{array}{l}\text { Intravenous fluid (normal saline) } 500 \text { mL every } 12 \\
\text { hours after fasting }\end{array}$ \\
\hline $\begin{array}{l}\text { Preoperative carbohydrate- } \\
\text { loaded drink }\end{array}$ & $\begin{array}{l}\text { Polycal Powder (Nutricia Advanced Medical Nutrition, } \\
\text { United Kingdom) } \times 500 \mathrm{~mL} \text { the evening before surgery }\end{array}$ & No \\
\hline \multicolumn{3}{|l|}{ Day of surgery } \\
\hline Pre-anaesthetic medication & No & No \\
\hline Anaesthetic management & $\begin{array}{l}\text { - Induction with fentanyl } 1 \mu \mathrm{g} / \mathrm{kg} \text {, propofol } 2 \mathrm{mg} / \mathrm{kg} \\
\text { (or TCl propofol at Ce } 4-5 \mu \mathrm{g} / \mathrm{mL} \text { ), and rocuronium } \\
0.6 \mathrm{mg} / \mathrm{kg} \\
\text { - Anaesthesia maintained with propofol infusion } \\
4-8 \mathrm{mg} / \mathrm{kg} / \mathrm{h} \text { (or TCl propofol at Ce } 2-5 \mu \mathrm{g} / \mathrm{mL} \text { ) and } \\
\text { remifentanil infusion } 0.05-0.2 \mu \mathrm{g} / \mathrm{kg} / \mathrm{min} \\
\text { - Ventilation maintained with oxygen } 40 \% \text { in air } \\
\text { - Forced body heating (Bair Hugger }{ }^{\mathrm{TM}} \text { system } \\
\text { [3M Health Care, US] and warmed IV fluids) } \\
\text { - Give tramadol } 1 \mathrm{mg} / \mathrm{kg} \text { IV upon skin incision } \\
\text { - Give parecoxib } 40 \mathrm{mg} \text { IV after skin closure } \\
\text { - Prophylactic use of ondansetron } 4 \mathrm{mg} \mathrm{IV} \text { to prevent } \\
\text { - postoperative nausea and vomiting } \\
\text { - Target low central venous pressure } \\
\text { - Fluid restricted until specimen removed; then fluid } \\
\text { restriction of crystalloid solution to } 10 \mathrm{~mL} / \mathrm{kg} / \mathrm{hr} \text { and } \\
\text { titrate with urinary output of }>0.5 \mathrm{~mL} / \mathrm{kg} / \mathrm{h} \\
\text { - Intra-operative blood loss to be replaced with colloid } \\
\text { solution }\end{array}$ & $\begin{array}{l}\text { - Induction with fentanyl } 1 \mathrm{\mu g} / \mathrm{kg} \text {, propofol } 2 \mathrm{mg} / \mathrm{kg} \text {, } \\
\text { and rocuronium } 0.6 \mathrm{mg} / \mathrm{kg} \\
\text { - Anaesthesia maintained with sevoflurane } 0.5 \% \text { - } \\
1.5 \% \text { and oxygen } 40 \% \text { in air } \\
\text { - Forced body heating (Bair hugger system and } \\
\text { warmed IV fluids) } \\
\text { - Give morphine } 0.1 \mathrm{mg} / \mathrm{kg} \text { IV upon skin incision } \\
\text { - Use of metoclopramide for postoperative nausea } \\
\text { - No restriction on intra-operative fluid management }\end{array}$ \\
\hline
\end{tabular}

Abbreviations: $\mathrm{CBP}=$ complete blood picture; $\mathrm{Ce}=$ effect site; CRP = C-reactive protein; ERAS = enhanced recovery after surgery; INR = international normalised ratio; IV = intravenous; PCA = patient-controlled analgesia; RLFT = renal and liver function tests; TCI = target-controlled infusion; $V A S=$ visual analogue scale 


\section{Discharge criteria}

Patients could be discharged if they fulfilled the discharge criteria, which consisted of (1) adequate pain control with oral analgesics, (2) absence of nausea, (3) ability to tolerate solid food, (4) liver function on an improving trend, (5) mobilisation and self-support as compared to the preoperative level, and (6) acceptance of discharge by the patient.

\section{Main outcome measures}

The primary outcome of the study was total postoperative hospital stay, including that of patients readmitted within 30 days after surgery. The secondary outcomes of the study included the readmission rate and morbidity and mortality within 30 days.

TABLE I. (cont'd)

\begin{tabular}{|c|c|c|}
\hline & Fast-track perioperative programme & Conventional perioperative programme \\
\hline \multicolumn{3}{|l|}{ Day of surgery } \\
\hline Surgical management & $\begin{array}{l}\text { - Right subcostal incision with midline extension for } \\
\text { open hepatectomy } \\
\text { - Minimally invasive incisions for laparoscopic } \\
\text { hepatectomy } \\
\text { - Infiltration of wounds with } 0.25 \% \text { levobupivacaine } \\
0.2 \mathrm{~mL} / \mathrm{kg} \\
\text { - Continuous wound instillation with } 0.25 \% \\
\text { levobupivacaine using the ON-Q Pain Buster (I-Flow } \\
\text { Corporation, Lake Forest [CA], United States) at } \\
2 \mathrm{~mL} / \mathrm{h} \text { for } 48 \mathrm{~h} \text { (in minimally invasive liver resection } \\
\text { if wound }>5 \mathrm{~cm} \text { ) or at } 4 \mathrm{~mL} / \mathrm{h} \text { for } 72 \mathrm{~h} \text { (in open liver } \\
\text { resection) } \\
\text { - Urinary catheter } \\
\text { - No abdominal drain; no nasogastric tube } \\
\text { - Elastic stockings and intermittent pneumatic } \\
\text { compression machine are used } \\
\text { - Body-warming device used }\end{array}$ & $\begin{array}{l}\text { - Right subcostal incision with midline extension for } \\
\text { open hepatectomy } \\
\text { - Minimally invasive incisions for laparoscopic or } \\
\text { robot-assisted laparoscopic hepatectomy } \\
\text { - No infiltration of surgical wounds with local } \\
\text { anaesthetic drug } \\
\text { - Urinary catheter } \\
\text { - Use of abdominal drain whenever necessary }\end{array}$ \\
\hline $\begin{array}{l}\text { Early postoperative } \\
\text { management }\end{array}$ & $\begin{array}{l}\text { - To high-dependency unit } \\
\text { - Allow fluid diet when fully awake + IV infusion of } \\
\text { crystalloid solution } 1.5 \mathrm{~L} / \text { day } \\
\text { - Give incremental doses of fentanyl } 10 \mathrm{\mu g} \text { IV if severe } \\
\text { pain in recovery room } \\
\text { - Add oral tramadol } 50 \mathrm{mg} \text { plus paracetamol } 1 \mathrm{~g} 3 \\
\text { times per day for } 3 \text { days as postoperative analgesia } \\
\text { - Consider oral or intramuscular tramadol } 50 \mathrm{mg} \text { for } \\
\text { rescue pain if VAS } \geq 4 \\
\text { - For minimally invasive hepatectomy: Sit in chair in the } \\
\text { evening (>2 h out of bed) } \\
\text { - Check CBP, RLFT, INR, CRP, glucose }\end{array}$ & $\begin{array}{l}\text { - Give incremental doses of morphine } 1 \mathrm{mg} \text { IV if } \\
\text { severe pain in recovery room } \\
\text { - Postoperative analgesia provided by IV PCA } \\
\text { morphine for } 3 \text { days (add oral tramadol } 50 \mathrm{mg} \\
\text { plus paracetamol } 1 \mathrm{~g} 3 \text { times per day from day } 2 \\
\text { onwards) } \\
\text { - 'Nil by mouth' + IV infusion of crystalloid solution } \\
2 \text { L/day } \\
\text { - No mobilisation scheme }\end{array}$ \\
\hline Day 1 after surgery & $\begin{array}{l}\text { - Offer soft diet } \\
\text { - 'Extra' sugar-free gum (The Wrigley Company [HK] } \\
\text { - Ltd) } 3 \text { times per day } \\
\text { - Stop IV fluid (leave cannula) } \\
\text { - Remove urinary catheter } \\
\text { - Remove central line and arterial line (if any) } \\
\text { bed); deep breathing exercise } \\
\text { - Check CBP, RLFT, INR, CRP, glucose } \\
\text { - Pain team assessment and removal of IV PCA and } \\
\text { continuous wound instillation pump if pain control } \\
\text { satisfactory }\end{array}$ & $\begin{array}{l}\text { - 'Sips of water' orally } \\
\text { - No chewing gum } \\
\text { - IV fluid administration } 2 \text { L/day } \\
\text { - Mobilisation according to attending surgeon }\end{array}$ \\
\hline Day 2 after surgery & $\begin{array}{l}\text { - Offer normal diet } \\
\text { - 'Extra' sugar-free gum (The Wrigley Company [HK] } \\
\text { - Ltd) } 3 \text { times per day } \\
\text { - Remove IV cannula } \\
\text { - bed); deeep breathing exercise } \\
\text { - Check CBP, RLFT, INR, CRP, glucose } \\
\text { - Pain team assessment and removal of IV PCA and } \\
\text { continuous wound instillation pump if pain control } \\
\text { satisfactory }\end{array}$ & $\begin{array}{l}\text { - Diet increases on daily basis } \\
\text { - No chewing gum } \\
\text { - IV fluid administration is continued until adequate } \\
\text { oral intake achieved } \\
\text { - Removal of urinary catheter and abdominal drain at } \\
\text { discretion of attending surgeon } \\
\text { - Mobilisation according to attending surgeon }\end{array}$ \\
\hline Day 3 after surgery & Continue as on day 2 until discharge criteria are fulfilled & $\begin{array}{l}\text { Continue as on day } 2 \text { until discharge criteria are } \\
\text { fulfilled }\end{array}$ \\
\hline
\end{tabular}




\section{Propensity score matching analysis}

The clinical outcomes of patients who underwent liver resection and received the ERAS programme were compared with those who received a conventional perioperative programme in the same period. Propensity score matching analysis was performed to control for potential bias. Sex, age, number of co-morbidities, ASA grade, diagnosis, presence of cirrhosis, and type of resection were chosen as our baseline covariates to calculate each patient's propensity score. The propensity scores were estimated by fitting a logistic regression model with the above covariates. The patients were then matched by their propensity scores using one-to-one nearest neighbour matching without replacement.

\section{Statistical analyses}

Statistical analyses and propensity score matching calculations were performed using SPSS (Windows version 20.0; IBM Corp, Armonk [NY], US), Chi squared tests (or Fisher's exact tests, when appropriate) were used to compare categorical data. Mann-Whitney $U$ tests were used to compare continuous, non-normally distributed outcomes between treatment groups. A two-sided $\mathrm{P}<0.05$ was considered to be statistically significant.

\section{Results}

A total of 20 patients who underwent liver resection at Prince of Wales Hospital, Hong Kong, from September 2015 to July 2016, were recruited into the ERAS programme. Their median age was 58 years (range, 33-77 years). The majority $(n=19,95 \%)$ of the patients were in ASA grade II. Hepatocellular carcinoma $(n=13,65 \%)$ and colorectal liver metastasis $(n=5,25 \%)$ were the main indications for operation. All patients had Child-Pugh score class A. Major and minor hepatectomy were performed in eight $(40 \%)$ and $12(60 \%)$ patients, respectively. Minimally invasive hepatectomy (laparoscopic or robotic) were performed in nine patients, and the remaining 11 (55\%) patients received open hepatectomy. There were no major complications as defined by the Clavien-Dindo classification of surgical complications, and no patients required readmission..$^{24,25}$ Only two (10\%) patients developed minor complications, which were wound seroma $(n=1,5 \%)$ and urinary retention $(n=1,5 \%)$.

The demographics of patients in the ERAS and conventional perioperative programme groups were comparable (Table 2). Perioperative outcomes are summarised in Table 3. There were no significant differences in patient demographics, liver function,

TABLE 2. Comparison of patient demographics between ERAS and conventional perioperative programme*

\begin{tabular}{|c|c|c|c|c|}
\hline & $\begin{array}{l}\text { ERAS programme } \\
(n=20)\end{array}$ & $\begin{array}{c}\text { Conventional } \\
\text { programme }(n=20)\end{array}$ & $\begin{array}{l}\text { Standardised } \\
\text { mean difference }\end{array}$ & $P$ value \\
\hline Male sex & $11(55 \%)$ & $12(60 \%)$ & -0.10 & $0.749 \dagger$ \\
\hline Age (years) & $58(33-77)$ & $62.5(41-74)$ & -0.08 & $0.779 \ddagger$ \\
\hline BMI $\left(\mathrm{kg} / \mathrm{m}^{2}\right)$ & $23.1(19.6-30.1)$ & $25.1(19.3-29.9)$ & -0.38 & $0.253 \ddagger$ \\
\hline No. of co-morbidities & $1(0-5)$ & $1(0-4)$ & 0.10 & $0.904 \ddagger$ \\
\hline ASA grade & & & & $>0.999 \S$ \\
\hline I & $1(5 \%)$ & $2(10 \%)$ & -0.19 & \\
\hline II & 19 (95\%) & $18(90 \%)$ & 0.19 & \\
\hline III & 0 & 0 & 0 & \\
\hline Diagnosis & & & & $0.819 \S$ \\
\hline $\mathrm{HCC}$ & $13(65 \%)$ & $11(55 \%)$ & 0.21 & \\
\hline Liver metastasis & $5(25 \%)$ & $6(30 \%)$ & -0.11 & \\
\hline Others & $2(10 \%)$ & $3(15 \%)$ & -0.15 & \\
\hline Presence of cirrhosis & $6(30 \%)$ & $5(25 \%)$ & 0.11 & $0.723 \dagger$ \\
\hline Type of resection & & & & $0.519 \dagger$ \\
\hline Open & $11(55 \%)$ & $13(65 \%)$ & -0.21 & \\
\hline Laparoscopic/robotic & $9(45 \%)$ & $7(35 \%)$ & 0.21 & \\
\hline Major versus minor hepatectomy & $8(40 \%)$ vs $12(60 \%)$ & $5(25 \%)$ vs $15(75 \%)$ & 0.32 & $0.331+$ \\
\hline
\end{tabular}

Abbreviations: ASA = American Society of Anesthesiologists; BMI = body mass index; ERAS = enhanced recovery after surgery; HCC $=$ hepatocellular carcinoma

* Data are shown as No. (\%) of patients or median (range), unless otherwise stated

+ Chi squared test

‡ Mann-Whitney $U$ test

$\S$ Fisher's exact test 
TABLE 3. Operative outcomes*

\begin{tabular}{|c|c|c|c|}
\hline & ERAS programme $(n=20)$ & $\begin{array}{l}\text { Conventional programme } \\
\qquad(n=20)\end{array}$ & $P$ value \\
\hline Operating time (min) & $227.5(145-450)$ & $230(73-405)$ & $0.718 \dagger$ \\
\hline Intra-operative blood loss (mL) & $210(10-1740)$ & $200(20-900)$ & $0.659 \dagger$ \\
\hline Transfusion & 0 & 0 & NA \\
\hline Postoperative hospital stay & $5(2-8)$ & $6(3-23)$ & $0.033 \dagger$ \\
\hline Open hepatectomy & $5(3-8)$ & $6(5-23)$ & $0.018 \dagger$ \\
\hline Laparoscopic/robotic hepatectomy & $4(2-8)$ & $5(3-8)$ & $0.681 \dagger$ \\
\hline Overall complications & $2(10 \%)$ & $4(20 \%)$ & $0.661 \ddagger$ \\
\hline Major & 0 & 0 & NA \\
\hline Minor & $2(10 \%)$ & $4(20 \%)$ & $0.661 \ddagger$ \\
\hline Readmission & 0 & 0 & NA \\
\hline
\end{tabular}

Abbreviations: ERAS = enhanced recovery after surgery; NA = not applicable

* Data are shown as median (range) or No. (\%) of patients

+ Mann-Whitney $U$ test

$\neq$ Fisher's exact test

tumour characteristics, or surgical techniques between the two groups. When compared with the conventional perioperative programme, the ERAS programme was associated with a significantly shorter postoperative hospital stay (5 vs 6 days, $\mathrm{P}=0.033)$. There was no significant difference in rates of postoperative complications or readmission.

\section{Discussion}

Results from the present study indicate that the ERAS programme is safe and feasible in both open and laparoscopic liver resections in Hong Kong. There was a significant reduction in the length of postoperative hospital stay in the ERAS group.

Although ERAS programmes are not new, their development in liver resection has been relatively slow because of the operation's high complexity and the high frequency of underlying liver cirrhosis in this group of patients. Patients with liver cirrhosis who undergo liver resection have special concerns that require special attention. Because the ERAS principles for liver resection were adapted from colonic surgery, more evidence is needed to prove the benefits of ERAS in liver resection and to tailor the elements of ERAS to liver resection.

For example, most ERAS programmes in open liver surgery use thoracic epidural analgesia. However, patients who undergo liver surgery experience transient coagulopathy after the operation, which may increase the risk of spinal hematoma if epidural analgesia is used. One previous study indicated that epidural analgesia increases the risk of bleeding and prolongs prothrombin time after liver resection. ${ }^{26}$ Furthermore, the majority of patients with liver cancer in our locality also had co-existing liver cirrhosis. This group of patients is coagulopathic even before liver resection, and the risk of bleeding complications related to the epidural analgesic is a particular concern. ${ }^{27}$ In the present study, we used an infusion pump for continuous infiltration of the wound with local anaesthetic agents for pain control in patients who underwent open liver resection. The acute pain service provided regular ward rounds to review pain control. Other analgesics would be added if pain control was unsatisfactory. We have previously studied the analgesic efficacy of this infusion pump in open liver surgery and found that total morphine consumption was reduced in patients who received continuous wound instillation of local anaesthetic after open liver surgery. This technique also effectively reduced pain at rest and after spirometry. ${ }^{28}$ The small size of the device can facilitate early mobilisation during the postoperative period. Recent recommendations of ERAS guidelines for liver surgery suggest that routine thoracic epidural analgesia is not recommended and that a wound infusion catheter is a good alternative. ${ }^{29}$

Restrictive use of surgical site drains after operation is one of the key elements of most ERAS protocols to support early mobilisation and reduce postoperative pain and discomfort. ${ }^{30}$ Recent metaanalyses did not recommend routine abdominal drainage in elective uncomplicated hepatectomy. ${ }^{31}$ However, cirrhotic patients are at risk of developing ascites and bleeding after liver resection. Therefore, according to the ERAS society recommendations for perioperative care for liver surgery, the available evidence is inconclusive, and no recommendation can be given either for or against the use of prophylactic drainage after hepatectomy. ${ }^{29}$ Data from larger studies are needed to evaluate the role of intra-abdominal drains in this specific group of patients. 
Nevertheless, ERAS protocols might still be beneficial to cirrhotic patients, particularly in regard to the omission of overnight fasting and carbohydrate loading. Cirrhotic patients have decreased hepatic glycogen storage and impaired gluconeogenesis: an overnight fast is equivalent to a fast of 2 to 3 days in a healthy person. Omission of overnight fasting and carbohydrate loading may lessen the nutritional stress for these patients.

Shorter hospital stays have been reported after minimally invasive liver resection. ${ }^{23,32,33}$ Whether a similar decrease in hospital stay can be achieved by open surgery with an optimised fasttrack programme remains unclear. In the current series, length of hospital stay was reduced by 1 day in both the minimally invasive and open surgery groups. However, only the difference in the open surgery group reached statistical significance. The major limitation of our study is its small sample size. Therefore, it did not have enough power to demonstrate statistical significance in small differences. Early reports on ERAS in liver surgery have demonstrated a significant reduction in hospital stay by 2 to 6 days. ${ }^{34-36}$ Some might contend that it was careful selection of patients that resulted in the reduction of length of stay. However, diverse groups publishing on consecutive series with ERAS principles have shown consistent results..$^{30}$ It is highly likely that the ERAS protocol can shorten hospital stays. However, whether it can lead to a reduction in healthcare costs will be the focus of future studies in this field. Another limitation of this study is the uncertainty of balance of characteristics between the two groups. Standardised mean differences showed imbalances of some demographics (eg, body mass index and extent of hepatectomy) between the treatment groups, but the $\mathrm{P}$ values did not reach statistical significance. Again this is caused by the small sample size, which yields a model that is not sensitive enough to detect small differences.

\section{Conclusion}

The ERAS programme for liver resection is safe and feasible. It resulted in a reduction in hospital stay without an increase in morbidity and mortality. Larger-scale studies are needed to optimise the programme's elements and study its costeffectiveness.

\section{Author contributions}

All authors had full access to the data, contributed to the study, approved the final version for publication, and take responsibility for its accuracy and integrity.

Concept and design of study: CCN Chong, SKC Chan, PBS Lai.

Acquisition of data: WY Chung, YS Cheung, AKY Fung, AKW Fong, HT Lok.
Analysis or interpretation of data: CCN Chong.

Drafting of the article: CCN Chong.

Critical revision for important intellectual content: PBS Lai, SKC Chan, KF Lee, J Wong.

\section{Acknowledgement}

We would like to thank Mr Philip Ip for his statistical support in this project.

\section{Conflicts of interest}

As an editor of the journal, PBS Lai was not involved in the peer review process. Other authors have no conflicts of interest to disclose.

\section{Declaration}

The results of this project were presented in the 12th Biennial E-AHPBA Congress 2017 (23-26 May 2017, Mainz, Germany) and in the RCSEd/CSHK Conjoint Scientific Congress 2018 (15-16 September 2018, Hong Kong).

\section{Funding/support}

This project was supported by a Direct Grant from the Chinese University of Hong Kong (Ref No: MD14705).

\section{Ethics approval}

The study was approved by the Joint Chinese University of Hong Kong-New Territories East Cluster Clinical Research Ethics Committee (CREC 2015.024).

\section{References}

1. Kehlet H, Wilmore DW. Evidence-based surgical care and the evolution of fast-track surgery. Ann Surg 2008;248:18998

2. Basse L, Raskov HH, Hjort Jakobsen D. Accelerated postoperative recovery programme after colonic resection improves physical performance, pulmonary function and body composition. Br J Surg 2002;89:446-53.

3. Kehlet H. Multimodal approach to postoperative recovery. Curr Opin Crit Care 2009;15:355-8.

4. Lemmens L, van Zelm R, Borel Rinkes I, van Hillegersberg $\mathrm{R}$, Kerkkamp H. Clinical and organizational content of clinical pathways for digestive surgery: a systematic review. Dig Surg 2009;26:91-9.

5. Spanjersberg WR, Reurings J, Keus F, van Laarhoven CJ. Fast track surgery versus conventional recovery strategies for colorectal surgery. Cochrane Database Syst Rev 2011;(2):CD007635.

6. Khoo CK, Vickery CJ, Forsyth N, Vinall NS, Eyre-Brook IA. A prospective randomized controlled trial of multimodal perioperative management protocol in patients undergoing elective colorectal resection for cancer. Ann Surg 2007;245:867-72.

7. Gatt M, Anderson AD, Reddy BS, Hayward-Sampson P, Tring IC, MacFie J. Randomized clinical trial of multimodal optimization of surgical care in patients undergoing major colonic resection. Br J Surg 2005;92:1354-62.

8. Bray F, Ferlay J, Soerjomataram I, Siegel RL, Torre LA, Jemal A. Global cancer statistics 2018: GLOBOCAN estimates of incidences and mortality worldwide for 36 cancers in 185 countries. CA Cancer J Clin 2018;68:394-424.

9. Benzoni E, Molaro R, Cedolini $\mathrm{C}$, et al. Liver resection 
for HCC: analysis of causes and risk factors linked to postoperative complications. Hepatogastroenterology 2007;54:186-9.

10. Karanjia ND, Lordan JT, Fawcett WJ, Quiney N, Worthington TR. Survival and recurrence after neoadjuvant chemotherapy and liver resection for colorectal metastases: a ten year study. Eur J Surg Oncol 2009;35:83843.

11. Jensen LS, Mortensen FV, Iversen MG, Jørgensen A, Kirkegaard P, Kehlet H. Liver surgery in Denmark 20022007 [in Danish]. Ugeskr Laeger 2009;171:1365-8.

12. Kehlet H. Fast-track surgery-an update on physiological care principles to enhance recovery. Langenbecks Arch Surg 2011;396:585-90.

13. Varadhan KK, Lobo DN, Ljungqvist O. Enhanced recovery after surgery: the future of improving surgical care. Crit Care Clin 2010;26:527-47,x.

14. Muller S, Zalunardo MP, Hubner M, Clavien PA, Demartines N; Zurich Fast Track Study Group. A fasttrack program reduces complications and length of hospital stay after open colonic surgery. Gastroenterology 2009;136:842-7.

15. Wind J, Hofland J, Preckel B, et al. Perioperative strategy in colonic surgery; LAparoscopy and/or FAst track multimodal management versus standard care (LAFA trial). BMC Surg 2006;6:16.

16. Polle SW, Wind J, Fuhring JW, Hofland J, Gouma DJ, Bemelman WA. Implementation of a fast-track perioperative care program: what are the difficulties? Dig Surg 2007;24:441-9.

17. Kehlet H. Fast-track colorectal surgery. Lancet 2008;371:791-3.

18. Pruthi RS, Nielsen M, Smith A, Nix J, Schultz H, Wallen EM. Fast track program in patients undergoing radical cystectomy: results in 362 consecutive patients. J Am Coll Surg 2010;210:93-9.

19. Barletta JF, Miedema SL, Wiseman D, Heiser JC, McAllen $\mathrm{KJ}$. Impact of dexmedetomidine on analgesic requirements in patients after cardiac surgery in a fast-track recovery room setting. Pharmacotherapy 2009;29:1427-32.

20. Hansen CT, Sørensen M, Møller C, Ottesen B, Kehlet H. Effect of laxatives on gastrointestinal functional recovery in fast-track hysterectomy: a double-blind, placebocontrolled randomized study. Am J Obstet Gynecol 2007;196:311.e1-7.

21. Andersen LØ, Gaarn-Larsen L, Kristensen BB, Husted H, Otte KS, Kehlet H. Subacute pain and function after fasttrack hip and knee arthroplasty. Anaesthesia 2009;64:50813.

22. Das-Neves-Pereira JC, Bagan P, Coimbra-Israel AP, et al. Fast-track rehabilitation for lung cancer lobectomy: a fiveyear experience. Eur J Cardiothoracic Surg 2009;36:383-
91.

23. Lee KF, Chong CN, Wong J, Cheung YS, Wong J, Lai P. Long-term results of laparoscopic hepatectomy versus open hepatectomy for hepatocellular carcinoma: a casematched analysis. World J Surg 2011;35:2268-74.

24. Clavien PA, Barkun J, de Oliveira ML, et al. The ClavienDindo classification of surgical complications: five-year experience. Ann Surg 2009;250:187-96.

25. Dindo D, Demartines N, Clavien PA. Classification of surgical complications: a new proposal with evaluation in a cohort of 6336 patients and results of a survey. Ann Surg 2004;240:205-13.

26. Sakowska M, Docherty E, Linscott D, Connor S. A change in practice from epidural to intrathecal morphine analgesia for hepato-pancreato-biliary surgery. World J Surg 2009;33:1802-8.

27. Ho AM, Lee A, Karmakar MK, et al. Hemostatic parameters after hepatectomy for cancer. Hepatogastroenterology 2007;54:1494-8.

28. Chan SK, Lai PB, Li PT, et al. The analgesic efficacy of continuous wound instillation with ropivacaine after open hepatic surgery. Anaesthesia 2010;65:1180-6.

29. Melloul E, Hübner M, Scott M, et al. Guidelines for perioperative care for liver surgery: enhanced recovery after surgery (ERAS) society recommendations. World J Surg 2016;40:2425-40.

30. Ljungqvist $O$, Scott $M$, Fearon KC. Enhanced recovery after surgery: a review. JAMA Surg 2017;152:292-8.

31. Gavriilidis P, Hidalgo E, de'Angelis N, Lodge P, Azoulay D. Re-appraisal of prophylactic drainage in uncomplicated liver resections: a systematic review and meta-analysis. HPB (Oxford) 2017;19:16-20.

32. Nguyen KT, Laurent A, Dagher I, et al. Minimally invasive liver resection for metastatic colorectal cancer: a multiinstitutional, international report of safety, feasibility, and early outcomes. Ann Surg 2009;250:842-8.

33. Kazaryan AM, Pavlik Marangos I, Rosseland AR, et al. Laparoscopic liver resection for malignant and benign lesions: ten-year Norwegian single-center experience. Arch Surg 2010;145:34-40.

34. Lee A, Chiu CH, Cho MW, et al. Factors associated with failure of enhanced recovery protocol in patients undergoing major hepatobiliary and pancreatic surgery: a retrospective cohort study. BMJ Open 2014;4:e005330.

35. van Dam RM, Hendry PO, Coolsen MM, et al. Initial experience with a multimodal enhanced recovery programme in patients undergoing liver resection. Br J Surg 2008;95:969-75.

36. Stoot JH, van Dam RM, Busch OR, et al. The effect of a multimodal fast-track programme on outcomes in laparoscopic liver surgery: a multicentre pilot study. HPB (Oxford) 2009;11:140-4. 